\title{
Propriedade intelectual e organização da P\&D vegetal: evidências preliminares da implantação da Lei de Proteção de Cultivares ${ }^{1}$
}

\author{
Sergio Medeiros Paulino de Carvalho* \\ Sergio L. M. Salles-Filho** \\ Sonia R. Paulino***
}

Resumo: $\mathrm{O}$ artigo discute como o processo de reconhecimento de direitos de melhoristas, na forma de proteção de cultivares, no Brasil se fez a partir de uma estratégia nacional de articular propriedade intelectual e desenvolvimento tecnológico nacional. A proteção intelectual é entendida como mecanismo de articulação e coordenação entre os agentes envolvidos no processo de inovação. A metodologia de coleta de dados consistiu na análise dos titulares de cultivares protegidas no Brasil disponibilizados pelo Serviço Nacional de Proteção de Cultivares, cruzando esses dados com os constantes do relatório de acompanhamento da produção de sementes no Brasil, elaborado pela Embrapa em parceria com o Ministério da Agricultura e a Abrasem. Entre as principais conclusões está a de que o processo de reorganização da pesquisa pública, por meio de parcerias estruturadas em torno do desenvolvimento de novos cultivares contribuiu fortemente para a manutenção da presença pública no mercado de sementes, todavia, varia entre as espécies pesquisadas.

\footnotetext{
${ }^{1}$ Baseado na tese de Doutorado do primeiro autor, Propriedade Intelectual na Agricultura, defendida no DPCT do IG/Unicamp em dezembro de 2003, orientada por Sergio Salles-Filho e a co-orientadora Sonia Paulino.

*Doutor em Política Científica e Tecnológica (DPCT/IG/Unicamp), Coordenador de Articulação Institucional do Instituto Nacional da Propriedade Industrial (INPI), Pesquisador Licenciado da Empresa de Pesquisa Agropecuária do Estado do Rio de Janeiro (PESAGRO-RIO) e Associado do GEOPI/Unicamp. sergio@ige.unicamp.br

**Professor Titular do Departamento de Política Científica e Tecnológica do Instituto de Geociências da Universidade Estadual de Campinas (Unicamp). sallesfi@ige.unicamp.br ***Doutora em Economia, Pesquisadora Associada do Grupo de Estudos sobre a Organização da Pesquisa e da Inovação (GEOPI).sonia.paulino@ige.unicamp.br
} 
Palavras-chave: proteção de cultivares, mercado de sementes, organização da pesquisa em melhoramento vegetal, complementaridade trajetória pesquisa pública e privada, UPOV, defesa concorrência.

Classificação JEL: Q16, 032, 034

Abstract: This article discusses the recent Brazilian strategy in the field of intellectual property rights applied to new varieties and seeds. Intellectual property is here understood as an economic tool to articulate and to coordinate the economic and technical agents involved in the process of development and diffusing of new varieties and seeds. The article deals with data from the National Service on Variety Protection and also with data from the Brazilian seed market. Among the main findings it shows that the recent strategy of EMBRAPA (the national public research institution) along with the recent emergence of foundations of seed production and commercialization (formed by small seed producers in different regions of the country), has caused important changes in the seed market structure. Of course, this movement has not been equal among all species and all market branches, but it is actually impressive among some of them (like corn and soybean seed markets). In this process, public research institutions can play an important role, especially if they are capable to build strong capabilities in dealing not only with genetics and seed production, but also with the national and the international regulatory frameworks.

Key words: Breeders rights, seed market, research in plant breeding, public and private complementary partnership, UPOV, anti-trust police

JEL classification: Q16, 032, 034

\section{Introdução}

Como decorrência da assinatura do Acordo TRIPs pelo Brasil foi feito reconhecimento de proteção para fármacos, alimentos e, particularmente, plantas, alterando a legislação relativa à propriedade intelectual no Brasil e implicando numa redefinição institucional. O artigo se propõe discutir 
como o processo de reconhecimento de direitos de melhoristas, na forma de proteção de cultivares, no Brasil se fez a partir de uma estratégia nacional de articular propriedade intelectual e desenvolvimento tecnológico nacional. Nesse sentido verificou-se a incorporação de preceitos das duas Atas que regulam o acordo internacional que baliza a matéria, a União para a Proteção de Obtenções Vegetais (UPOV). Essa estratégia compôs-se com outra, formulada e executada pela Embrapa, no sentido de reestruturar e reorganizar a estrutura de pesquisa vegetal no país, por meio de parcerias com instituições públicas e privadas, resultando numa nova articulação entre agentes econômicos atuantes no mercado de sementes. Como conseqüência, a presença pública nesse mercado foi consolidada. No entanto, a falta de políticas de defesa da concorrência e de regulação do mercado de sementes pode operar num sentido contrário, provocando impactos regressivos no tocante à capacitação científica e tecnológica nacional e na capacidade de formular e executar políticas de desenvolvimento do agronegócio nacional no setor estratégico de geração de material genético.

O artigo está estruturado em mais três seções, além desta introdução. A seção 2 apresenta a metodologia utilizada na análise da legislação implementada no Brasil sobre proteção de cultivares, assim como da base de dados empregada na estimativa dos impactos da legislação no mercado de sementes. A seção 3 se remete aos Resultados e Discussão desses dados e informações. Esta seção está subdividida em cinco partes: na primeira se discute o processo de reconhecimento de direitos de proteção de cultivares, explorando a lógica desse reconhecimento e explicitando as figuras utilizadas na legislação brasileira de cada Ata do tratado UPOV. A segunda analisa o processo de rearticulação da pesquisa em melhoramento vegetal desencadeado a partir da implantação da Lei de Proteção de Cultivares e da estratégia de estabelecimento de parcerias pela Embrapa. A terceira apresenta um panorama geral da utilização de cultivares protegidas no mercado brasileiro de sementes, enquanto na parte seguinte é feita uma análise específica da incorporação de cultivares proprietárias no segmento de soja, visto ser esse onde se apresentam de forma mais incisiva tanto as estratégias de articulação de parcerias do setor público de pesquisa quanto das empresas privadas. Por fim são apresentadas as conclusões 
Propriedade Intelectual e Organização da P\&D Vegetal: evidências preliminares da implantação da Lei de Proteção de Cultivares

\section{Metodologia}

Foi feita uma análise dos principais pontos da legislação brasileira de proteção de cultivares, comparando aspectos relacionados às Convenções ou Atas da UPOV utilizadas como referência.

Os dados referentes à incorporação de cultivares protegidas como material propagativo conformam outro tipo de apuração. Há um acompanhamento da produção de sementes no Brasil voltado para oito espécies. Visando estimar a importância da participação das cultivares protegidas produzidas como sementes na safra 2000/2001, foi feita uma análise cruzando os dados disponibilizados pelo Serviço Nacional de Proteção de Cultivares e os constantes do acompanhamento da produção de sementes no Brasil feito pelo Ministério da Agricultura, pela Embrapa e pela Associação Brasileira de Produtores de Sementes (Abrasem).

As listagens foram cruzadas da seguinte forma: entre as cultivares que tiveram produção aprovada para cada uma das oito espécies monitoradas, foram identificadas as que fazem parte da Listagem de Cultivares Protegidas do Serviço Nacional de Proteção de Cultivares que constavam na atualização de 20 de fevereiro de 2003.

Entre os elementos analisados estão a área destinada à produção de sementes por espécie e para cada cultivar; a produção aprovada pela autoridade responsável como semente, produção essa que é denominada como produção de sementes; e o valor atribuído à produção de sementes aprovada, estimado para o ano de 2001. Cabe ressaltar que o valor estimado para as cultivares protegidas é o preço atribuído às cultivares não protegidas para cada espécie. Tal procedimento decorre da não apuração dos preços dos dois tipos de cultivares (protegidas ou não protegidas) no monitoramento do mercado brasileiro de sementes. Cabe, ainda, assinalar que os dados da produção de sementes no Brasil remetem-se à safra 2000/2001.

\section{Resultados e Discussão}

\subsection{Proteção às Inovações Vegetais no Brasil}

A legislação em vigor no Brasil assimilou aspectos constantes das Revisões (ou Atas) de 1978 e de 1991. A Revisão da UPOV de 1978 pre- 
via que as variedades protegidas deveriam ser distintas, homogêneas e estáveis, e a exceção do agricultor e do melhorista. Proibia a dupla proteção (simultaneamente por direitos de melhorista e por patentes), ao mesmo tempo em que possibilitava aos países definir quais espécies seriam protegidas (Wilkinson; Castelli, 2000).

A Revisão da UPOV de 1991 agregou a exigência da variedade ser nova (não ter sido colocada à venda anteriormente à solicitação de proteção por um período determinado de tempo - um ano no país onde for solicitado o registro ou quatro anos no caso de culturas e seis anos no de árvores e videiras). Introduziu a noção de variedade essencialmente derivada, exigindo que a variedade melhorada a partir de outra por número mínimo de características definido em lei, mantidas as características essenciais da variedade inicial, tenha a permissão do detentor dos direitos e pague royalties para o mesmo. O prazo de proteção foi ampliado de 15 para 20 anos para culturas e, pelo menos, 25 para árvores e videiras.

As principais características da legislação brasileira de proteção de cultivares, segundo Wilkinson e Castelli (2000) são as seguintes:

a - considerar a proteção de cultivares como a única forma de proteção e proibir a dupla proteção (Convenção de 1978); b - exigir que a variedade protegida seja distinta, homogênea, estável e nova (Convenção de 1991); c - estabelecer proteção para variedades essencialmente derivadas, incluindo derivação a partir de variedades reconhecidas como essencialmente derivadas (Convenção de 1991); d - reconhecer direito de proteção para todas as espécies, ressaltando, que estas serão definidas progressivamente, através de atos da autoridade competente.; e - reconhecer retroativamente, para fins de derivação essencial, variedades que não tenham sido colocadas à venda até dez anos antes da promulgação da lei, igualmente reconhecendo direitos sobre variedades que tenham sido comercializadas até 12 meses antes da solicitação de direitos de proteção; f - manter isenção do melhorista, ressalvando a exigência de autorização do titular do cultivar utilizado; g - proteger por prazo inferior ao estipulado pela Convenção de 1991 (15 anos para as variedades de culturas e 18 para árvores e videiras); 
Propriedade Intelectual e Organização da P\&D Vegetal: evidências preliminares da implantação da Lei de Proteção de Cultivares

\subsection{Titularidade dos Certificados de Proteção}

As instituições públicas de pesquisa nacionais detêm praticamente $40 \%$ do total de cultivares protegidas no Brasil. Conjugado com as cultivares protegidas de cooperativas e associações de produtores nacionais, chega-se a $60 \%$ do total. As empresas estrangeiras representam pouco mais de $25 \%$ do total. As espécies com maior número de variedades protegidas são a soja (praticamente a metade), o trigo e a cana-de-açúcar (em torno de $10 \%$ cada uma), a batata, o arroz e o algodão.

As empresas estrangeiras têm a maior participação em batatas. Representam $66 \%$ das variedades protegidas. Agregando-se a participação de cooperativas/associações de produtores estrangeiros, a participação de cultivares estrangeiras chega a $93 \%$. Já nas variedades protegidas de milho a participação das instituições públicas de pesquisa chega a $90 \%$ e a nacional (os 10\% restantes são cooperativas e associações de produtores nacionais) a $100 \%^{2}$.

Na cultura do trigo, a participação estrangeira restringe-se a uma variedade, de propriedade de empresa, equivalendo a pouco menos de $3 \%$. Cooperativas/associações de produtores e instituições públicas de pesquisa têm participações praticamente iguais, pouco abaixo de $40 \%$ cada. As empresas nacionais respondem por $24 \%$ das cultivares protegidas da espécie.

Em números absolutos, as empresas estrangeiras têm maior importância na soja. Esta concentra $70 \%$ das variedades protegidas que são de propriedade das empresas estrangeiras. Todavia, não representam mais do $38 \%$ do total de cultivares protegidas da espécie (soja).

O setor público de pesquisa continua central no processo de lançamento e proteção de novas cultivares. O processo de privatização e desnacionalização do setor sementeiro embora tenha ocorrido em algumas frentes, não foi generalizado. Ao contrário, a presença nacional continua marcante e expressiva, ainda que seja um tempo de análise curto (1998 a 2003) para afirmações peremptórias. Entretanto, as estratégias empresa-

\footnotetext{
${ }^{2}$ Cabe ressaltar a questão das formas jurídicas superpostas de proteção. O mecanismo mais eficiente para a proteção de híbridos de milho encontra-se na Lei de Propriedade Industrial, por meio do segredo de negócio. Dessa perspectiva, é natural que essa forma de proteção fosse mais utilizada por empresas, tanto nacionais quanto estrangeiras.
} 
riais, em especial das transacionais, afetaram fortemente o segmento de sementes de milho híbrido. Carvalho e Pessanha (2001), entendem que esse fenômeno se deu após a promulgação da Lei de Proteção de Cultivares, não necessariamente como decorrência da mesma. A concentração de quase $2 / 3$ desse segmento pela empresa norte-americana Monsanto, em 1999, decorre das possibilidades da ampliação da difusão de tecnologias de base biotecnológica e da própria estratégia dessa empresa.

A Monsanto também adotou estratégias agressivas em relação à soja, que explicam, em grande parte, a participação estrangeira na titularidade de certificados de proteção de cultivares nessa espécie. A Monsanto comprou a FT Sementes, empresa nacional que produz sementes de reconhecida qualidade nacional e internacional, ao mesmo tempo em que articula uma estratégia de licenciamento do gene Roundup Ready para inserção em variedades de terceiros (Carvalho, 2003).

\subsection{Estratégias de Articulação de Parcerias e Reorganização da Pesquisa Pública}

A participação do setor público no mercado de sementes é decorrência também da capacitação no manejo dos mecanismos de proteção à propriedade intelectual.

A Embrapa estabeleceu políticas e regulamentou as parcerias para o desenvolvimento de novas variedades de plantas. Estas são divididas em termos de sua natureza (parcerias com entes privados e com entes públicos) e do aporte de recursos humanos, materiais e financeiros. A Embrapa considera que a apropriação exclusiva dos direitos de propriedade intelectual das cultivares que desenvolve é um imperativo estratégico nacional (Embrapa, 2000a; 2000b).

Assim, a parceria com entes privados tem um caráter fortemente monitorado. A co-titularidade não é admitida em hipótese alguma. Não se admite, igualmente, a cooperação no caso da empresa privada manter programa próprio de melhoramento genético para a espécie objeto do programa conjunto de desenvolvimento vegetal, seja diretamente ou por interposta pessoa, ou ainda disponibilize suas instalações para outrem que mantenha programa de melhoramento genético. Com essa ressalva, a Embrapa evita a possibilidade de que 
Propriedade Intelectual e Organização da P\&D Vegetal: evidências preliminares da implantação da Lei de Proteção de Cultivares

seu material genético seja misturado ao do parceiro privado (Embrapa, 2000a; Cunha, 2003).

As parcerias privadas são articuladas em torno de fundações de direito privado, com a finalidade específica de desenvolver, produzir e licenciar novas cultivares de plantas. Essas fundações conferem flexibilidade aos parceiros em termos de licenciamento das cultivares, alocação e utilização de recursos financeiros, humanos e materiais. A interação entre os parceiros é delimitada e especificada em termos de obrigações e direitos, tendendo a diminuir os custos de transação associados ao empreendimento. As fundações podem envolver a Embrapa e entes privados e, eventualmente, públicos.

\subsection{Cultivares Protegidas no Mercado Brasileiro de Sementes}

O total de cultivares protegidas (342) das oito espécies monitoradas representam parte expressiva do total de certificados outorgados pelo SNPC, ou seja, $85 \%$ dos 399 certificados de proteção de cultivares emitidos até fevereiro de 2003.

Chama atenção a importância da soja no total de cultivares protegidas. Com 184 cultivares protegidas a espécie representava, em fevereiro de 2003 , mais da metade $(53,8 \%)$ do total de cultivares protegidas. Do grupo de oito espécies cuja produção de sementes é monitorada no Brasil, o trigo é a segunda espécie em importância, representando 11,4\% das cultivares protegidas no mesmo período. Em terceiro lugar aparecem empatadas duas espécies, o algodão e o arroz ${ }^{3}$; ambas têm 30 cultivares protegidas, equivalentes a $8,8 \%$ do total de certificados outorgados pelo SNPC. O milho encontra-se em quinto lugar entre as oito espécies monitoradas, sendo seus 23 cultivares equivalentes a 6,7\% dos certificados expedidos. Com 22 cultivares protegidas, a batata representa 6,4\% do total, situando-se em sexto lugar entre as espécies monitoradas. A cultura do feijão congrega um número reduzido, situando suas 13 cultivares protegidas em sétimo lugar, com 3,8\% do total. A participação das

${ }^{3}$ O monitoramento das sementes de arroz apresenta uma segmentação adicional, a saber, as sementes destinadas ao plantio de sequeiro e irrigado. No entanto, como a proteção legal é feita considerando a espécie (arroz) e não o sistema de produção a que se destina a semente (sequeiro ou irrigado), a espécie será analisada em conjunto. 
forrageiras entre as cultivares protegidas é irrisória, apenas uma cultivar foi protegida em 2003.

Em termos da utilização de cultivares protegidas no mercado de sementes, a participação relativa das duas espécies mais importantes, a soja e o trigo, aumenta. Os 105 cultivares protegidas de soja representaram $66,4 \%$ do total de cultivares protegidas comercializadas como sementes, enquanto os 20 cultivares de trigo significaram $12,7 \%$ do total em questão. O arroz também manteve a terceira posição, com participação relativa de 9,5\% . O algodão apresentou 6,25\%, situandose em quarto lugar. O feijão tem menor participação relativa, ocupando a quinta posição, à frente da batata. A única forrageira protegida não foi utilizada como semente no período analisado, visto ter sido protegida posteriormente.

Essa situação é decorrente da incorporação diferenciada das variedades protegidas no processo produtivo. Para o conjunto das espécies, pouco menos da metade das cultivares protegidas $(46,2 \%)$ foi produzido como semente na safra 2000/2001. A soja foi a espécie que apresentou o maior índice de incorporação de cultivares protegidas no processo produtivo daquela safra. Essa participação foi de 57,1\% . A cultura do trigo apresenta também uma forte incorporação das cultivares protegidas no processo produtivo, com 51,3\%. Esse patamar é o mesmo verificado para o arroz, espécie para a qual o índice de incorporação é de $50 \%$. O algodão situa-se em 33,3\% . O feijão situa-se no mesmo patamar, com 30,8\% utilizados como sementes na safra 2000/2001. O milho tem $17,4 \%$ das cultivares utilizadas como sementes, enquanto a batata apresenta $9,1 \%$.

Em termos da produção aprovada como semente e a importância relativa das cultivares protegidas utilizadas como material propagativo, a soja e o trigo apresentaram participação na safra 2000/2001 de 83,21 \% e de $10,89 \%$, respectivamente. Ou seja, as cultivares protegidas de soja respondiam no período analisado por uma proporção da produção de sementes $(83,21 \%)$ significativamente maior que a participação das cultivares protegidas $(57,1 \%)$ em relação ao total em uso para a espécie. No caso do trigo, a participação da produção de sementes (10,89\%) mantém correlação entre a quantidade de cultivares em uso como sementes $(11,4 \%)$. Nas demais espécies, a participação das cultivares protegidas na produção de sementes é bem inferior à verificada para a quantidade 
Propriedade Intelectual e Organização da P\&D Vegetal: evidências preliminares da implantação da Lei de Proteção de Cultivares

de cultivares protegidas em relação ao total em uso como sementes. Das demais espécies, o arroz e o algodão posicionaram-se acima de $1 \%$. No caso do arroz, a participação estimada na produção de sementes ficou pouco abaixo dos $4 \%$, ficando em seguida o algodão com 0,76\%. A batata posicionou-se ligeiramente abaixo de $1 \%$, o milho participando com $0,45 \%$ da produção para a sua espécie e o feijão com $0,23 \%$.

A relevância da soja em termos da utilização de cultivares protegidas e da estimativa da participação destes no que toca ao total do valor das sementes proprietárias, ressalta a sua importância. É, ainda, nessa espécie que aparecem de forma incisiva os arranjos decorrentes das parcerias articuladas pela pesquisa pública, a presença de empresa transnacional e de associações de produtores. A próxima seção faz uma análise da espécie.

\subsection{Cultivares Protegidas de Soja no Brasil}

A utilização de sementes produzidas a partir de cultivares protegidas de soja apresenta um quadro bastante variado, no qual estão presentes distintos agentes econômicos: arranjos institucionais representados pelas parcerias públicas promovidas pela Embrapa e desta com entidades privadas; empresas nacionais e multinacionais; associações de produtores e instituições estaduais de pesquisa agropecuária são titulares de cultivares protegidas utilizadas como sementes na safra 2000/2001, como se deduz da Tabela 1.

Os principais titulares de cultivares protegidas são as instituições públicas de pesquisa nacionais, com 39\%, as empresas privadas estrangeiras com $38 \%$ e as organizações de produtores ou fundações a elas ligadas, com $20 \%$. As empresas nacionais e as universidades detêm posições marginais, participando com 1,5\% cada do total de cultivares protegidas. Sete cultivares protegidas estão entre os dez mais importantes na safra 2001/2002 (Embrapa, 2002).

A Embrapa é o agente econômico de maior relevância na produção de sementes protegidas de soja. Individualmente, detém $23 \%$ da titularidade das cultivares protegidas da espécie, porém computando-se suas parcerias, essa participação sobe para 36\%. A Embrapa detém individualmente a titularidade de $27 \%$ das cultivares protegidas utilizadas na produção de 
sementes e, considerando-se as parcerias, a participação passa a ser de $41 \%$. A participação individual da Embrapa na produção de sementes proprietárias é de $16 \%$ e em conjunto com as instituições parceiras, $28 \%$.

Tabela 1 - Cultivares de Soja Protegidas no Brasil, por Titular e segundo o número de cultivares, a utilização como sementes e o seu valor estimado, safra 2000/2001

\begin{tabular}{|c|c|c|c|c|c|c|}
\hline \multirow{3}{*}{ Principais Titulares } & \multicolumn{6}{|c|}{ Discriminação } \\
\hline & \multicolumn{2}{|c|}{$\begin{array}{l}\text { Cultivares } \\
\text { Protegidas }\end{array}$} & \multicolumn{2}{|c|}{$\begin{array}{c}\text { Cultivares em } \\
\text { Uso } \\
\text { Como Semente }\end{array}$} & \multicolumn{2}{|c|}{ Produção Aprovada } \\
\hline & Unid. ${ }^{1}$ & $\%$ & Unid. ${ }^{1}$ & $\%$ & Toneladas $^{2}$ & $\%$ \\
\hline Embrapa + Parceiros & 67 & 36 & 43 & 41 & 216.918 & 28 \\
\hline Embrapa & 42 & 23 & 28 & 27 & 121.720 & 16 \\
\hline Monsoy (Monsanto) & 55 & 30 & 24 & 23 & 89.356 & 12 \\
\hline Coodetec & 19 & 10 & 14 & 13 & 94.496 & 12 \\
\hline Pioneer & 8 & 4 & 6 & 6 & 10.660 & 1 \\
\hline Fundação Mato Grosso (FMT) & 10 & 5 & 5 & 5 & 598 & 0 \\
\hline Outros Titulares & 25 & 14 & 13 & 12 & 14.984 & 2 \\
\hline Total de Cultivares Protegidos & 184 & 100 & 105 & $100 / 52^{3}$ & 427.011 & $100 / 56^{4}$ \\
\hline Total & 184 & 100 & 201 & 100 & 765.093 & 100 \\
\hline
\end{tabular}

Fonte: Embrapa (2002c), www.agricultura.gov.br/snpc, acesso em fevereiro de 2003, cálculos do autor.

${ }^{1}$ Número de cultivares protegidas e em uso como sementes.

${ }^{2}$ Volume de sementes básicas obtidas com os cultivares em uso como sementes.

${ }^{3}$ Porcentagem das Cultivares Protegidas sobre o total de Cultivares usadas na safra 2000/01.

Em termos da titularidade de cultivares protegidas, a Monsanto, através da empresa Monsoy, tem uma posição superior à da Embrapa, quando esta é considerada individualmente. A Monsoy é titular de 55 cultivares protegidas ( $30 \%$ do total), dos quais 13 são para fins de transgenia. Essa participação decresce para $23 \%$ quando são considerados as cultivares protegidas utilizadas como sementes na safra 2000/2001. Levando-se em conta a participação das cultivares que têm como titular a Monsoy, esta corresponde a menos de $12 \%$ do total produzido como semente. Assim, a Monsoy passa a ocupar a segunda posição em termos 
Propriedade Intelectual e Organização da P\&D Vegetal: evidências preliminares da implantação da Lei de Proteção de Cultivares

de cultivares protegidas utilizadas na produção de sementes e ocupa a terceira posição no quesito quantidade produzida de sementes a partir de cultivares protegidas, na safra 2000/2001.

Outro agente econômico relevante é a Coodetec, vinculada à Organização das Cooperativas do Paraná (OCEPAR). Participa com 10\% dos certificados de proteção de cultivares, sendo 3 para fins de derivação e 3 para fins de transgenia. Sua participação sobe para pouco mais de $13 \%$ quando se considera a utilização de cultivares protegidas, ficando a participação na quantidade de sementes de cultivares protegidas em $12 \%$.

Tanto a Embrapa (seja individualmente ou em parceria) quanto a Coodetec são titulares de cultivares de sucesso comercial. A Embrapa e seus parceiros têm a titularidade de 3 cultivares protegidas situadas entre as 10 mais importantes utilizadas como sementes na safra 2000/2001, com participação na quantidade aprovada que variaram de 3,5\% a 8,3\%. Já a Coodetec possui igualmente três cultivares no mesmo ranking, com participação individual variando entre 2,6\% e 3,1\%. Entre as cultivares protegidas da Monsoy, nenhum se situa entre os 10 mais produzidos. $\mathrm{O}$ cultivar que tem a maior participação no mercado é M-Soy 8914, alcançando 2,1\% da produção aprovada para a safra aludida.

A análise da participação dos agentes pode ser enriquecida ao se retomar as trajetórias da Embrapa, da Coodetec e da Monsoy no segmento de soja. Tanto as instituições públicas de pesquisa quanto as organizações de produtores rurais tendem a ter um papel relevante na geração e no processo de adoção de tecnologia, em particular onde a capacidade de apropriação da inovação gerada tende a ser baixa. Com a exceção das sementes de híbridos, onde características biológicas ampliam a capacidade de apropriação, as empresas privadas apresentam pouco interesse na participação de melhoramento de espécies autógamas, cujas sementes são passíveis de reaproveitamento pelo produtor rural.

É interessante notar que os três agentes econômicos em questão mantêm uma trajetória de atuação complementar que possibilita a convivência num ambiente fortemente competitivo. Há um processo de co-evolução desses agentes concomitante às mudanças institucionais experimentadas, particularmente com a adoção do estatuto de proteção de cultivares.

Wilkinson e Castelli (2000) e Santini (2002) consideram que durante a expansão da cultura da soja no Brasil na década de 1970, a geração 
de cultivares da espécie pelo setor público mostrava-se insuficiente para atender às necessidades do mercado nacional. A utilização então de sementes contrabandeadas colocava em xeque a organização do mercado, assim como restringia violentamente o acesso ao crédito, fortemente subsidiado à época. A liberação de crédito para os produtores dependia da utilização de sementes recomendadas, fazendo com que a rentabilidade dos produtores (e de suas organizações) se visse afetada pela oferta insuficiente de sementes. A entrada de sementeiras privadas nessa cultura vincula-se à possibilidade de fazer acordos com as cooperativas, assim como dessas cooperativas e organizações de produtores estabelecerem programas próprios de melhoramento e geração de novas cultivares de soja. Essa situação manteve-se com o processo de avanço da soja para novas áreas (os Cerrados brasileiros são exemplo por excelência), exigindo geração de novas cultivares adaptadas às áreas de expansão.

A FT Sementes ${ }^{4}$ desde a década de 1960 percebeu as possibilidades que a sojicultura apresentava e tornou-se pioneira no desenvolvimento de novas cultivares. Estes não só tiveram grande sucesso no Paraná, como também se mostraram altamente adaptados às condições do Cerrado brasileiro. O mecanismo de remuneração da empresa era através de acordos com cooperativas, pelos quais a FT Sementes era remunerada à base de $2,5 \%$ das vendas realizadas para os cooperados. Esse arranjo, por um lado, ampliava a área que utilizava as cultivares da FT e, por outro lado, garantia a manutenção do programa e o lançamento de novas cultivares, consolidando a posição da empresa no segmento. Deste ponto de vista, a lógica de atuação da FT se aproximava mais da de uma organização de produtores do que da lógica de uma empresa industrial ${ }^{5}$. Desde 1995, a FT Sementes estabeleceu um programa de cooperação com a Monsanto (inclusive para inserção de genes), pelo qual vendia pesquisa para a empresa americana, até ter a operação em soja vendida para a criação da Monsoy, ao final da década de 1990 (Carvalho, 1996b; Wilkinson e Castelli, 2000; Santini, 2002).

\footnotetext{
${ }^{4}$ Cabe insistir que seu programa de melhoramento, assim como os cultivares desenvolvidos foram incorporadas pela Monsanto na empresa Monsoy

${ }^{5}$ Esse tipo de arranjo mostra-se funcional até os dias atuais, possibilitando, inclusive, uma participação expressiva da FT no sub mercado de sementes protegidas de feijão, como demonstra Carvalho (2003).
} 
Propriedade Intelectual e Organização da P\&D Vegetal: evidências preliminares da implantação da Lei de Proteção de Cultivares

A Coodetec entrou no melhoramento vegetal de soja tanto como um desdobramento da capacitação alcançada quanto pela necessidade de gerar cultivares adaptadas às condições específicas do Paraná, visto que as cultivares utilizadas inicialmente eram os oriundos do Rio Grande do Sul. A capacidade de difusão das cultivares que gerava, possibilitou à Coodetec fazer com que suas cultivares fossem majoritárias na sua área de atuação principal, o Paraná (Wilkinson e Castelli, 2000). A entrada em vigor da Lei de Proteção de Cultivares permitiu à Coodetec, a partir de sua estrutura de distribuição e assistência técnica, manter-se competitiva no novo quadro, no qual esses atributos representam elementos de diferenciação (Carvalho, 1996b).

Já a Embrapa, cujo programa de distribuição e comercialização de sementes consolidou-se a partir da década de 1980, conduziu, inicialmente, seu programa de melhoramento de soja a partir do Centro Nacional de Pesquisa em Soja (CNPSo), no Paraná. Além de desenvolver pesquisas com material próprio, também atua em articulação com empresas e institutos estaduais públicos de pesquisa. Essa articulação permitiu à Embrapa ganhar capilaridade no processo de desenvolvimento e adaptação do material gerado às condições locais, dentro da lógica da sua missão de instituição pública de desenvolvimento de pesquisa e de coordenadora do sistema de pesquisa agropecuária nacional (Carvalho, 1996a).

Igualmente, a articulação com organizações de produtores permitiu tanto uma maior adequação das cultivares às condições objetivas de produção quanto distribuição eficiente entre os produtores. Todavia, essas relações se redefiniram frente ao novo quadro institucional, sendo utilizada a figura de fundações para serem estabelecidas novas relações contratuais entre a Embrapa e seus parceiros, situação analisada na seção anterior. O que cabe ressaltar para fins da presente análise é o impacto que o novo quadro institucional teve nos arranjos para o desenvolvimento de cultivares proprietárias. Além dos números analisados referentes à participação no segmento de soja, chama a atenção a ênfase dos arranjos da Embrapa e seus parceiros na área de Cerrados. As parcerias envolvem os estados de Minas Gerais, Goiás, Mato Grosso, Mato Grosso do Sul. Ou seja, esses arranjos possibilitaram à Embrapa cobrir a área de expansão e consolidação da soja, fora dos limites do seu centro de pesquisa. Dentro da lógica de fonte de dinamismo tecnológico, a Embrapa também conse- 
guiu incorporar a perspectiva de atuação de organização de produtores, atuando diretamente em parcerias que garantem capilaridade e difusão em massa de suas cultivares.

Finalizando a análise dos impactos da LPC no segmento de soja, pode-se destacar que a mudança no quadro institucional derivada do reconhecimento de direitos de obtentor provocou uma forte reestruturação. O primeiro ponto que chama a atenção é a redução da participação das empresas nacionais. Igualmente ampliou-se a participação de empresas multinacionais. São movimentos articulados, na medida que a redução de uma e ampliação de outra foram decorrência, principalmente, da compra do programa de soja da FT Sementes pela Monsanto, que resultou na formação da Monsoy.

Por outro lado, há uma redefinição do espaço de intervenção pública, por meio das estruturas oficiais de pesquisa. Essa redefinição não implicou em perda de importância da pesquisa pública, mas levou a uma nova forma de atuação. As articulações com parceiros tradicionais públicos, que se formaram a partir da década de 1970, passaram a ganhar uma mediação, que são as fundações, incisivamente presentes no segmento de soja. Essa articulação é responsável pela ampliação da participação da Embrapa na quantidade de cultivares utilizadas como sementes na safra 2000/2001 em pouco mais de 50\%, em relação à participação individual da instituição federal. Em termos da quantidade de sementes produzidas, a participação da Embrapa ampliou-se em 78\%. E essa capilaridade é alcançada nas áreas de expansão e consolidação da cultura da soja, além de ganhar acesso a organizações de produtores. Deste ponto de vista, o impacto pode ser entendido como altamente positivo.

\section{Conclusões}

A articulação institucional promovida pela Embrapa, organizando parcerias voltadas tanto para o desenvolvimento de novas variedades proprietárias, assim como licenciando essas e demais variedades desenvolvidas individualmente pela empresa federal são exemplos de que é possível tratar a propriedade intelectual como elemento de interação, que facilita uma invenção/inovação circular entre os diversos agentes econômicos e atores que participam do processo de inovação, tanto no que 
Propriedade Intelectual e Organização da P\&D Vegetal: evidências preliminares da implantação da Lei de Proteção de Cultivares

diz respeito à relação público/privado, quanto público/público. Dessa forma, os principais agentes (pesquisa pública, empresa multinacional e organização de produtores rurais) estabelecem complementaridade em suas trajetórias.

Os mecanismos de proteção à propriedade intelectual são relevantes para a organização e coordenação da pesquisa agrícola, fortalecendo a institucionalidade da pesquisa pública como um todo, dando uma nova conotação para o Sistema Nacional de Pesquisa Agropecuária, que inclui, além da Embrapa, as organizações estaduais de pesquisa agropecuária e as universidades.

Em relação à presença nacional no segmento de sementes de soja, a estratégia da empresa líder (Monsanto), ampliou a presença transnacional e reduziu a participação de empresas nacionais como decorrência da incorporação da empresa nacional mais importante. Todavia esse movimento não desaguou num processo de desnacionalização. Isso foi possível basicamente como decorrência do processo de coordenação da pesquisa pública no segmento em questão, assim como da forte presença de organização de produtores. Dessa forma, o fato de ter ocorrido deslocamento da empresa privada nacional, as características da organização das fontes de dinamismo da agricultura ensejaram uma presença nacional marcante. A forte presença da Monsanto, por intermédio da Monsoy, não lhe garantiu presença majoritária. Esta é da Embrapa, individualmente e para o conjunto dos seus parceiros.

O outro grande titular de cultivares protegidas e utilizados com é uma organização de produtores (COODETEC), com larga experiência no desenvolvimento e distribuição de cultivares de soja. É interessante notar que a organização em questão, de forte presença no estado do Paraná, mantinha acordo de distribuição e remuneração dos materiais da FT Sementes antes dessa se articular e ser comprada pela Monsanto. A indicação oferecida pela participação da COODETEC é a de que a capacitação prévia e a articulação com os usuários/produtores rurais são relevantes elementos de apropriação que se complementam com os estatutos legais.

O quadro favorável à produção de sementes por empresas nacionais, de porte regional e reguladoras de preços, não prescinde de uma política industrial e de inovação voltada para o setor e para as estratégias de 
organização das relações público privado. A regulação da concorrência é, neste cenário, essencial para que se mantenha essa trajetória virtuosa de relação entre base tecnológica inovadora, capacitação institucional e uso criativo dos instrumentos de propriedade. Nada garante a longevidade desse modelo, nem que as forças de mercado venham a se afeiçoar por esse tipo de organização. Muito pelo contrário, a história mostra que essas formas alternativas de organização da produção são vítimas potenciais da força do capital.

\section{Referências bibliográficas}

CARVALHO, S. M. P. Propriedade intelectual na agricultura. Tese de Doutorado, Instituto de Geociências, Universidade Estadual de Campinas, DPCT/IG/UNICAMP, 2003.

CARVALHO, S. M. P. A importância da superação do paradigma produtivista pelos Sistemas Estaduais de Pesquisa. Brasília: Cadernos de Ciência e Tecnologia, v.13, n.1, 1996a.

CARVALHO, S. M. P. Proteção de Cultivares no Contexto de Outros Mecanismos de Apropriabilidade: possíveis impactos no mercado brasileiro de sementes. Dissertação de Mestrado, Universidade Estadual de Campinas, DPCT/IG/UNICAMP, 1996b.

CARVAlHO, S. M. P. e PESSANHA, L. D. R. Propriedade intelectual, estratégias empresariais e mecanismos de apropriação do esforço de inovação no mercado brasileiro de sementes. Revista de Economia Contemporânea, Rio de Janeiro, 5(1), 151-182, jan./jun, 2001.

Embrapa - Empresa Brasileira de Pesquisa Agropecuária. Deliberação $\mathrm{N}^{0} 14 / 2000$, de 05 de maio de 2000, relativa à cooperação técnica com parceiro da iniciativa privada. Brasília, Embrapa, 2000a.

Embrapa - Empresa Brasileira de Pesquisa Agropecuária. Deliberação $N^{0} 15 / 2000$, de 05 de maio de 2000, relativa à cooperação técnica com parceiro da iniciativa privada. Brasília, Embrapa, 2000b.

Embrapa - Empresa Brasileira de Pesquisa Agropecuária. A Produção de Sementes no Brasil: relatório da safra 2000/2001. Brasília: Embrapa/Ministério da Agricultura, Pecuária e Abastecimento/Abrasem, 2002. 
SANTINI, G. A. A reestruturação da indústria de sementes no Brasil: o novo ambiente concorrencial dos segmentos de milho híbrido e soja. DEP/UFSCAR:2002.

WILKINSON, J.; CASTELLI, P. G. A Transnacionalização da indústria de sementes no Brasil - biotecnologias, patentes e biodiversidade. Rio de Janeiro: ActionAid Brasil 2000.

Recebido em julho 2005 e revisto em junho de 2006 